\title{
More Comprehensive Care Among Family Physicians is Associated with Lower Costs and Fewer Hospitalizations
}

\author{
Andrew Bazemore, MD, MPH \\ Stephen Petterson, $\mathrm{PbD}^{1}$ \\ Lars E. Peterson, $M D, P b D^{2}$ \\ Robert L. Pbillips Jr, MD, MSPH ${ }^{2}$ \\ 'Robert Graham Center, Washington, DC \\ ${ }^{2}$ The American Board of Family Medicine, \\ Lexington, Kentucky
}

Conflicts of interest: authors report none.

\section{CORRESPONDING AUTHOR}

Andrew W. Bazemore, MD, MPH

Robert Graham Center

1133 Connecticut Avenue, NW Suite 100

Washington, DC 230036

ABazemore@aafp.org

\begin{abstract}
PURPOSE Comprehensiveness is lauded as 1 of the 5 core virtues of primary care, but its relationship with outcomes is unclear. We measured associations between variations in comprehensiveness of practice among family physicians and healthcare utilization and costs for their Medicare beneficiaries.
\end{abstract}

METHODS We merged data from 2011 Medicare Part A and B claims files for a complex random sample of family physicians engaged in direct patient care, including $100 \%$ of their claimed care of Medicare beneficiaries, with data reported by the same physicians during their participation in Maintenance of Certification for Family Physicians (MC-FP) between the years 2007 and 2011. We created a measure of comprehensiveness from mandatory self-reported survey items as part of MC-FP examination registration. We compared this measure to another derived from Medicare's Berenson-Eggers Type of Service (BETOS) codes. We then examined the association between the 2 measures of comprehensiveness and hospitalizations, Part B payments, and combined Part A and B payments.

RESULTS Our full family physician sample consists of 3,652 physicians providing the plurality of care to 555,165 Medicare beneficiaries. Of these, 1,133 recertified between 2007 and 2011 and cared for 185,044 beneficiaries. There was a modest correlation (0.30) between the BETOS and self-reported comprehensiveness measures. After adjusting for beneficiary and physician characteristics, increasing comprehensiveness was associated with lower total Medicare Part A and B costs and Part B costs alone, but not with hospitalizations; the association with spending was stronger for the BETOS measure than for the self-reported measure; higher BETOS scores significantly reduced the likelihood of a hospitalization.

CONCLUSIONS Increasing family physician comprehensiveness of care, especially as measured by claims measures, is associated with decreasing Medicare costs and hospitalizations. Payment and practice policies that enhance primary care comprehensiveness may help "bend the cost curve."

Ann Fam Med 2015;13:206-213. doi: 10.1370/afm.1787.

\section{INTRODUCTION}

7 he Patient Protection and Affordable Care Act (ACA) of 2009 has returned attention to primary care and its role in achieving the nation's Triple Aim of improved population health and patient care with lower costs. ${ }^{1}$ Decades of evidence support primary care's potential as an antidote to health care costs, whose growth has outpaced that of the overall economy for decades and may yet accelerate, given our aging, enlarging, and increasingly insured population. ${ }^{2,3}$ Among the definitional features of primary care thought to be responsible for its positive impact is comprehensiveness, or the provision of care across a broad spectrum of health problems, age ranges, and treatment modalities. The Institute of Medicine, in an often-referenced 1996 publication on primary care, defined comprehensiveness as "...the provision of integrated, accessible health care services by clinicians who are accountable for addressing a large majority of personal health care needs."' The value of this function of primary care was reiterated by the World Health Organization in 
2008. ${ }^{5}$ To serve as first contact for undifferentiated illness, another primary care principle, requires comprehensiveness to effectively differentiate symptoms and complaints, diagnose and treat where necessary. Likewise, continuity in the physician-patient relationship, one of the most studied of primary care features, relies upon comprehensiveness, as does coordination of the relationship across many settings. In theory, comprehensiveness is supposed to make delivery of "the right care, at the right time, in the right place" and the avoidance of more costly care later more likely.

Among primary care specialties, the traditional scope of family medicine is perhaps the broadest, including care for all patients, for all presenting complaints, across sites, ages, and modalities including inpatient, outpatient, obstetric, pediatric, geriatric, procedures, minor surgeries, and community health functions. Despite broad training, the general scope of care provided by family physicians has been shrinking. ${ }^{6,7-11}$ The credentialing and logistical challenges required to work across multiple delivery settings, competitive pressures from a growing array of specialty service providers, lifestyle demands, increasing complexity of chronic disease care, and market incentives to streamline practice leave the majority of family physicians working strictly in nonhospital, office-based settings, while a small but growing number function primarily as hospitalists or in emergency departments and urgent care facilities. ${ }^{12}$ Growing evidence reveals both reduction and considerable variation in the range of services offered by family physicians, which may have implications for costs of care. ${ }^{1,13,14}$

Despite these trends, the 2004 Future of Family Medicine Report noted that the discipline was "committed to providing the full basket of clinical services offered by family medicine..$^{15}$ With the 2014 release of Family Medicine for America's Health (FMAH), leaders are once again contemplating the future of the discipline, with some questioning whether erosion of scope of practice is a threat to the adaptiveness and pragmatism that shaped the discipline. ${ }^{16}$ This matter is of growing importance as policymakers consider new definitions of primary care that go beyond the traditional specialty-based definition, and in some cases, frame primary care as a simple process or seek to narrow its functions in the name of efficiency. ${ }^{17,18}$

Given the considerable advances in health care technology, our aging and more insured population, and considerable variation and decreasing scope of practice by family physicians, it is unknown whether comprehensiveness still has a positive effect on costs. We therefore set out to study the relationship between individual family physicians' comprehensiveness and important outcomes for their patients, namely hospitalization rates and total costs among their Medicare beneficiaries.

\section{METHODS}

\section{Sample}

The physicians included in our sample are drawn from a larger state-weighted sample of about 31,000 direct patient care physicians, including 4,930 family physicians, drawn from the 2010 American Medical Association Masterfile. Pediatricians and physicans with under 30 patients in their Medicare file were excluded. To allow for state-level estimates, we oversampled physicians in smaller states. We used this sample to procure a data set from the Center for Medicare and Medicaid Services (CMS) of all fee-for-service Medicare beneficiaries seen at least once by the physicians in our sample in 2011. In that year, 25\% of Medicare beneficiaries were enrolled in Medicare Advantage plans. For fee-for-service beneficiaries we obtained all of their Medpar and carrier Medicare claims (that is, Part A and Part B claims), regardless of whether the claims were associated with the sampled physicians.

Given that many beneficiaries see multiple primary care physicians in the course of a year, ${ }^{20}$ we restricted our analysis to Medicare beneficiaries aged 65 years or older who obtained the plurality of their primary care (that is, more than from any other physician) from a primary care physician in our sample, as described below.

\section{Linking Beneficiaries With Primary Care Physicians}

To assign each beneficiary to a single physician, we first excluded any physicians found to have more than $80 \%$ of their evaluation and management claims delivered in a hospital. ${ }^{21}$ We also restricted the claims data to the services performed by primary care physicians, including family physicians, general practitioners, general internists, geriatricians, and pediatricians. We then calculated for each beneficiary the number of services performed by each physician and identified the primary care physician providing the most services for the beneficiary. In cases of ties across physicians in performing the most services performed, 1 was selected at random. We then created a subsample restricted to family physicians who recertified with the American Board of Family Medicine (ABFM) between the years 2007 and 2011. This allowed us to link claims data with demographic and practice data provided by family physicians as a requirement of recertification.

\section{Two Measures of Comprehensiveness}

The first comprehensiveness measure we created used an ABFM dataset uniquely capable of capturing the practice patterns of family physicians. As part of the application for the maintenance of certification examination, all family medicine Diplomates are required to provide practice information, including the percent- 
Table 1. Percentages of Family Physicians Providing Select Services, ABFM Activities, and BETOS Codes

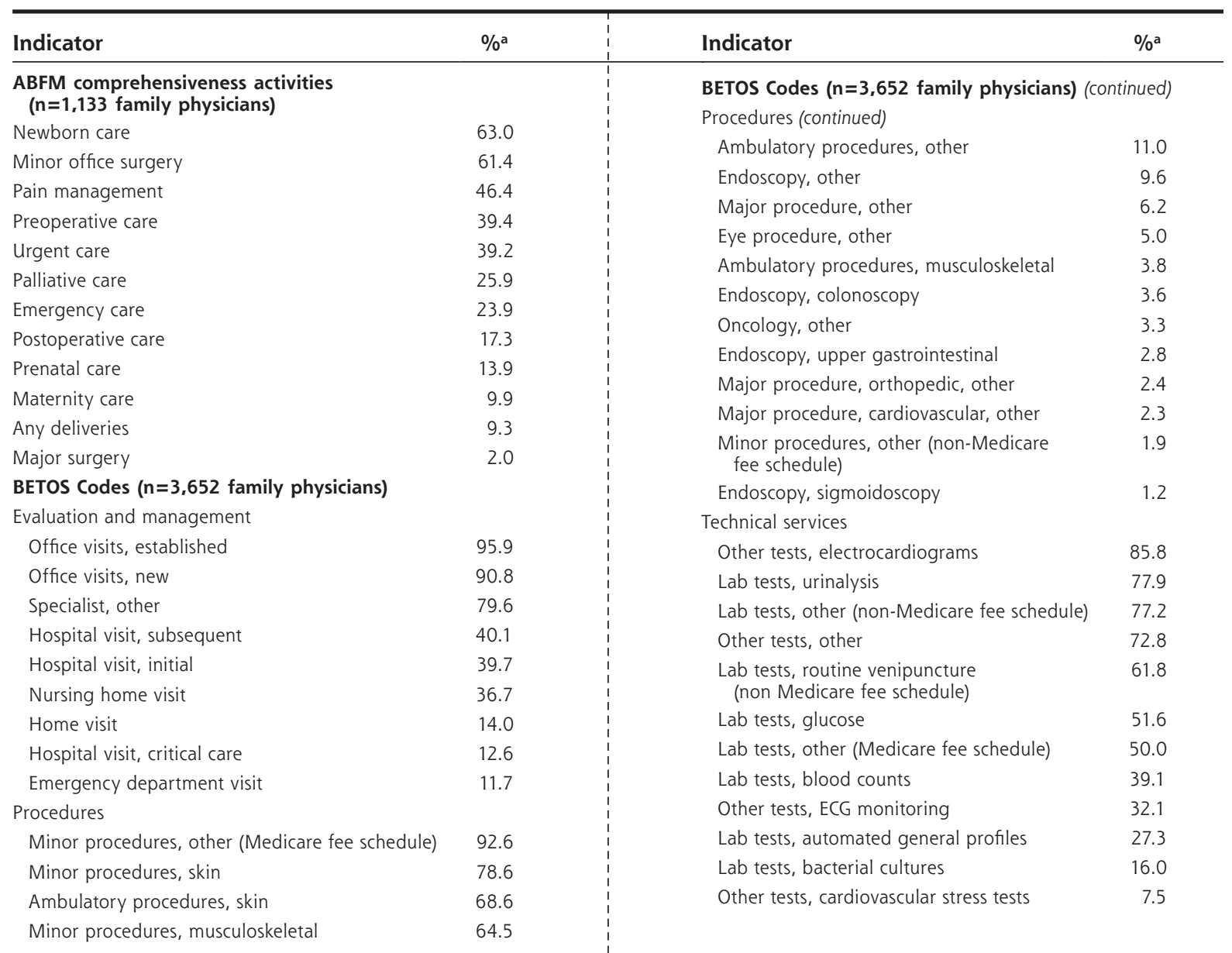

BETOS = Berenson-Eggers Type of Service; ABFM = American Board of Family Medicine.

apercentages of family physicians who indicated that they devoted any time to a particular activity in the case of the ABFM items or billed Medicare at least once for each type of BETOS service, procedure, or test.

ages of their time they devote to certain activities (Table 1). They are also asked whether they deliver babies or provide prenatal care and newborn care. We used this information to create a summative scale to measure comprehensiveness using 12 sites or content areas of practice: emergency care, urgent care, major surgery, maternity care, office surgery, pain management, palliative care, postoperative care, preoperative care, prenatal care, newborn care, and obstetrical deliveries. These items were selected to increase the discrimination of our scale. Comprehensiveness scores range from 0 to 12 .

A second measure, using Berenson-Eggers Type of Service (BETOS) codes, takes advantage of efforts to standardize and summarize the various types of current procedural terminology (CPT) codes used to bill for services in Medicare claims data. ${ }^{19}$ It gave us a simple way of characterizing the services each family physician provided to beneficiaries across a range of care settings and modalities (Table 1). We summed up the total number of different BETOS evaluation and management, procedural, and test services provided by a family physician that accounted for 90 percent of the total number of services they provided to Medicare beneficiaries in 2011. We excluded imaging and durable medical equipment codes, as well as a number of other codes billed at very low frequencies by family physicians. We included technical service codes such as laboratory testing, since they could be indirect indicators of more varied procedures necessitating their use. Possible BETOS scores range from 1 to $37_{i}$ in our sample the range was 1 to 32 . In preliminary analyses, we found a modest association $(r=0.30)$ between BETOS scores and ABFM comprehensiveness scores.

\section{Outcomes Measures}

We used several measures for all of the Medicare beneficiaries obtaining the plurality of their care from the 
family physicians in our sample. We calculated the following:

- Part B payments for each beneficiary, summing the payments made during 2011

- The total of Part A and Part B costs for each beneficiary

We used a logarithmic transformation for the charge measures because they were highly skewed; a small fraction of beneficiaries had very high charges. For our third measure, we identified patients with at least 1 hospitalization during 2011.

\section{Model Definition and Statistical Analyses}

We first used descriptive statistics and bivariate analyses to examine the associations between our 2 measures of comprehensiveness and a number of patient, geographic, and physician characteristics. We then examined the association between these measures of comprehensiveness and the 2 payment measures using multilevel linear regression. The data we are using is multi-level with patients nested within physicians. The standard errors are calculated allowing for correlation within clusters (physicians), but observations are independent across physicians. This was accomplished using the vce (cluster clustvar) command in Stata 13.1 (Stata Corp), which we used for all analyses.

Patient-level covariates included standard measures of age, sex, and race/ethnicity available from the CMS claims denominator file. We also used diagnosis information to construct a modified Charlson score for each patient as a measure of health and a method of risk adjustment. ${ }^{22}$ We also created a continuous variable from a simple count of the number of primary care visits for each beneficiary. All analyses were weighted to provide national-level estimates.

Geographic covariates were created by determining 2 geographic measures from the ZIP code where each family physician provided most of his or her care:

- Rurality, using streamlined Rural to Urban Commuting Codes (urban, large rural, small rural, isolated rural, and frontier)

- Dartmouth Atlas's 2011 estimate of the number of family physicians (FPs) per 100,000 in the beneficiaries/physicians' Hospital Referral Region (HRR) ${ }^{23,24}$

Physician variables were created from provider specialty information available from the claims data. From the American Medical Association Masterfile, we also determined whether the physician was an international medical school graduate (IMG), and his or her year of graduation from medical school.

All tests of significance were 2-sided; significant results were defined at $P<.05$. The American Academy of Family Physicians Institutional Review Board approved this study without restrictions.

\section{RESULTS}

Starting with our larger sample of about 31,000 physicians, we identified 8,290 primary care physicians who provided the plurality of care to $1,527,633$ beneficiaries. This figure dropped to $1,222,178$ after excluding patients less than 65 years of age, as well as patients of pediatricians and of physicians with fewer than 30 patients. A total of 555,165 beneficiaries obtained the plurality of their care from 3,652 family physicians. Finally, we identified 185,044 Medicare beneficiaries receiving a plurality of their care from 1,133 FPs who recertified between 2007 and 2011.

The percentages of family physicians who reported providing clinical services in the 12 areas covered by the ABFM comprehensiveness measure varied widely from area to area. For example, only $2 \%$ reported providing major surgery, while more than $60 \%$ reported caring for newborns (Table 1). The mean score for the ABFM comprehensiveness measure was 3.48, with a median of 3 and an interquartile range of 2-4. Similarly, physicians varied considerably in the provision of services as recoded using BETOS codes. For example, nearly all family physicians submitted claims for office visits with established (95.9\%) or new patients $(90.8 \%)$, but just $14 \%$ billed for home visits and $11.7 \%$ for emergency department visits (Table 1). BETOS scores (the count of different BETOS codes that account for $90 \%$ of the services provided by the physician in the course of a year) were normally distributed, with a mean of 15.05 , a median of 15 and an interquartile range of 13-18.

The patients treated by the family physicians who recertified in 2007-2011 were generally similar to those treated by the larger group of family physicians in our full sample (Table 2). The average age of beneficiaries cared for by the physicians in our sample was about 75 years. They had an average of 6 visits to a primary care physician per year. A little more than $60 \%$ of the patients treated by the family physicians were female, $83.7 \%$ to $85.9 \%$ were non-Hispanic whites.

Both measures of comprehensiveness are associated with other family physician characteristics (Table 3). IMGs have significantly lower BETOS scores than US medical school graduates $(P<.05)$; the difference in ABFM comprehensiveness scores between US and international medical graduates was not statistically significant. Female family physicians had lower BETOS scores than male family physicians on average, and allopathic physicians have slightly higher BETOS scores than osteopathic physicians. Family physicians who graduated from medical school more recently have significantly higher comprehensiveness scores but not BETOS scores. Physicians located in more rural areas and in regions with more family physicians per 
Table 2. Beneficiary and Physician Sample Characteristics

\begin{tabular}{|c|c|c|}
\hline & $\begin{array}{l}\text { All Family } \\
\text { Physicians }\end{array}$ & $\begin{array}{c}\text { Recertifying } \\
\text { Family Physicians }\end{array}$ \\
\hline Physicians (No.) & 3,652 & 1,133 \\
\hline Patients (No.) & 555,165 & 185,044 \\
\hline \multicolumn{3}{|l|}{ Patient characteristics } \\
\hline Female & $60.1 \%$ & $61.0 \%$ \\
\hline \multicolumn{3}{|l|}{ Race/ethnicity } \\
\hline White & $83.7 \%$ & $85.9 \%$ \\
\hline Black & $7.1 \%$ & $5.6 \%$ \\
\hline Hispanic & $5.6 \%$ & $4.7 \%$ \\
\hline Other race & $3.7 \%$ & $3.8 \%$ \\
\hline Age (mean) & 75.0 & 75.0 \\
\hline Weighted Charlson score (mean) & 1.25 & 1.23 \\
\hline Primary care visits & 6.04 & 6.08 \\
\hline \multicolumn{3}{|l|}{ Physician characterisitics } \\
\hline \multicolumn{3}{|l|}{ Location } \\
\hline Urban & $75.6 \%$ & $76.8 \%$ \\
\hline Large rural & $14.0 \%$ & $13.7 \%$ \\
\hline Small rural & $6.0 \%$ & $6.2 \%$ \\
\hline Isolated rural & $2.1 \%$ & $2.1 \%$ \\
\hline Frontier & $1.8 \%$ & $1.0 \%$ \\
\hline Years since graduation (mean) & 23.1 & 23.1 \\
\hline International medical school graduate & $14.0 \%$ & $11.1 \%$ \\
\hline Patients (mean) & 197.0 & 208.0 \\
\hline Female & $28.3 \%$ & $30.9 \%$ \\
\hline$\%$ Care in hospital & $7.3 \%$ & $7.8 \%$ \\
\hline
\end{tabular}

ness was associated with lower costs per beneficiary (Figure 2). The narrower 95\% confidence intervals compared with those for the ABFM scope analysis were attributable to the use of the full sample of family physicians $(n=3,652)$. There was a clear gradient showing that increasing comprehensiveness is associated with lower average payments per patient, whether using the Medicare Part A and B or the Part B payment measure. The odds ratios reported for the hospitalization outcome showed a large difference in the likelihood of a hospitalization between patients of physicians in the lowest BETOS quintile and those cared for by physicians in the other 4 quintiles, with less variation across the top 4 quintiles.

\section{DISCUSSION}

Using a large, nationally representative sample of family physicians, we found that patients of family physicians who reported performing and who billed for a broader range of services had lower costs and fewer hospitalizations. These findings confirm that comprehensiveness in family medicine is both measurable and important. Specifically, BETOS categories derived directly

capita have significantly higher scores on both the ABFM and the BETOS measures.

Our multivariate results examining the association of comprehensiveness with health service use are summarized in Figure 1. The underlying regression coefficients are reported in Supplemental Appendix 1, available at http://www.annfammed.org/content/13/3/206/suppl/ DC1. This analysis is restricted to family physicians who recertified between 2007 and $2011(n=1,133)$. The comprehensiveness measure appeared to have no association with the likelihood that a physician's patient was hospitalized. By contrast, for both payment measures, we found a negative association between comprehensiveness and Medicare payments for their patients. Controlling for beneficiary and physician differences, beneficiaries cared for by family physicians within the quintile with the highest comprehensiveness scores have total Part A and Part B expenses that are 10.3\% lower than those of patients cared for by physicians with the lowest comprehensiveness scores; a similar difference was evident for Part B costs alone, with a $12.8 \%$ difference between patients of patients of physicians in the highest and lowest quintiles.

The multivariate findings using the BETOS measure also indicated that increasing comprehensivefrom claims can be used to create a useful measure of comprehensiveness. The inverse relationship between greater comprehensiveness and 2011 total Part A and $\mathrm{B}$ costs and hospitalizations per Medicare beneficiary persisted even after controlling for important beneficiary and provider characteristics. Scope of services was broadest in rural locations, but rural-urban differences alone were not enough to explain away the impact of breadth on cost and utilization as measured.

This evidence arrives at a critical juncture for family medicine. In 2004, 7 national family medicine organizations declared that the Future of Family Medicine required a "commitment to provide patients with family medicine's full basket of services-either directly or indirectly." ${ }^{25}$ The landmark report reaffirmed that all family physicians were committed to providing "comprehensive...care for their patients," which was noted as one of the "core values... responsible for much that the public currently values and trusts in family physicians" and which "have shaped the identity of individual family physicians and contributed to establishing a legitimate position for family physicians in academia and in the larger medical community." ${ }^{125}$ Since the Future of Family Medicine report, however, family physicians are being asked to acquire and employ new 
skills in greater population health management, administration and leadership of teams, and informatics-all this while caring for an aging and increasingly multimorbid pool of patients..$^{26-30}$

As such, family medicine leaders are emerging from another existential debate, a yearlong discussion of what to be-or not to be. As the discipline unveils a new vision, "Family Medicine for America's Health," it is fair to examine the meaning of generalism ${ }^{31}$ and the importance of the traditional basket of services that have defined family medicine and its training paradigm for decades. ${ }^{14,15}$

Comprehensiveness remains one of the least studied functions of primary care. There is considerable evidence for the benefit of continuity and coordination, for example, but few studies have empirically

Table 3. Variation in Comprehensiveness and BETOS Scores Across Selected Characteristics of Family Physicians

\begin{tabular}{|c|c|c|c|c|}
\hline & $\begin{array}{c}\text { Comprehensiveness } \\
\text { Scores }\end{array}$ & $\begin{array}{l}\text { Recertifying } \\
\text { Family } \\
\text { Physicians }\end{array}$ & $\begin{array}{l}\text { BETOS } \\
\text { Scores }\end{array}$ & $\begin{array}{l}\text { Full Sample } \\
\text { of Family } \\
\text { Physicians }\end{array}$ \\
\hline \multicolumn{5}{|l|}{$\begin{array}{l}\text { Medical School } \\
\text { Location }\end{array}$} \\
\hline United States & 3.51 & 1042 & $13.86^{a}$ & 3,257 \\
\hline International & 3.12 & 91 & 12.27 & 395 \\
\hline \multicolumn{5}{|l|}{ Sex } \\
\hline Male & 3.46 & 771 & $14.04^{\mathrm{a}}$ & 2,549 \\
\hline Female & 3.49 & 362 & 12.60 & 1,103 \\
\hline \multicolumn{5}{|c|}{ Medical school type } \\
\hline Allopathic & 3.42 & 1048 & $13.73^{a}$ & 3,052 \\
\hline Osteopathic & 4.22 & 85 & 13.20 & 600 \\
\hline \multicolumn{5}{|c|}{$\begin{array}{l}\text { Year of medical } \\
\text { school graduation }\end{array}$} \\
\hline$<1980$ & $2.81^{b}$ & 211 & 13.53 & 731 \\
\hline 1980-1989 & 3.57 & 340 & 13.69 & 1,111 \\
\hline 1990-1999 & 3.66 & 571 & 13.68 & 1,302 \\
\hline$\geq 2000$ & 3.86 & 11 & 13.57 & 508 \\
\hline \multicolumn{5}{|l|}{ Practice location } \\
\hline Urban & $3.27^{b}$ & 760 & $13.44^{\mathrm{a}}$ & 2,421 \\
\hline Large rural & 3.71 & 214 & 13.92 & 673 \\
\hline Small rural & 4.65 & 91 & 14.71 & 290 \\
\hline Isolated rural & 4.77 & 45 & 14.41 & 158 \\
\hline Frontier & 5.60 & 22 & 16.29 & 89 \\
\hline \multicolumn{5}{|c|}{$\begin{array}{l}\text { Family physicians } \\
\text { per } 100,000 \\
\text { population }\end{array}$} \\
\hline $0-20$ & $2.44^{b}$ & 48 & $12.64^{\mathrm{a}}$ & 151 \\
\hline $21-40$ & 3.37 & 717 & 13.59 & 2,325 \\
\hline $41+$ & 4.25 & 368 & 14.15 & 1,176 \\
\hline \multicolumn{5}{|c|}{ Medicare Claims Data, 2011.} \\
\hline \multicolumn{5}{|c|}{ BETOS = Berenson-Eggers Type of Service codes. } \\
\hline \multicolumn{5}{|c|}{$\begin{array}{l}\text { Note: The mean comprehensiveness scores are based on the subsample of recertifying family physicians } \\
(n=1,133) \text {. Comprehensiveness scores for individual physicians range from } 0 \text { to } 12 \text {. The mean BETOS scores are } \\
\text { based on the full sample of family physicians }(n=3,652) \text {. BETOS scores range from } 1 \text { to } 32 \text {. }\end{array}$} \\
\hline
\end{tabular}

tested the value of comprehensiveness. This study offers important evidence about the value of broadspectrum care across settings for holding down utilization and cost. In the absence of such evidence, there is real risk of continued, unresisted erosion of family medicine's commitment to comprehensive care. There is also risk of active reduction in broad practice in the name of daily patient volume and efficiency. Passive and active reductions in comprehensiveness are both supported by a fee-for-service payment system, which makes comprehensive care less lucrative and more compromising to lifestyle than high-volume outpatient service delivery. There are also policy and credentialing pressures, advocates who herald the benefits of "intensivist-only ICUs" and hospitalist care, and more. ${ }^{7,13,32,33}$ With such forces driving the average family physician away from traditional elements of practice such as maternity care, hospital services, and the care of children, the discipline finds itself asking whether its 'core values' remain immutable. The discipline is left to flounder without effective branding or a strong public identity while the wholesale transformation of its practice platform proceeds apace.

Since our measures of comprehensiveness are exploratory and rely on large secondary datasets, they may not capture all dimensions of comprehensiveness nor all aspects of care provided by family physicians. Our Medicare study sample reflects mostly the elderly portion of the 'cradleto-grave' population cared for by family physicians, although they are ostensibly the most expensive. Furthermore, 1 of our measures of scope is based on self-reported data from a sample of family physicians recertifying over a 4-year period. We are unaware, however, of any comparable studies of family physicians' practice behaviors across a broad cohort of the discipline, a source used in an increasing number of peerreviewed publications. ${ }^{6,7,9,14,33,34}$ Furthermore, the Medicare beneficiary population is one with a high degree of service intensity 
Figure 1. Association between comprehensiveness score and measures of hospitalization and expenses.

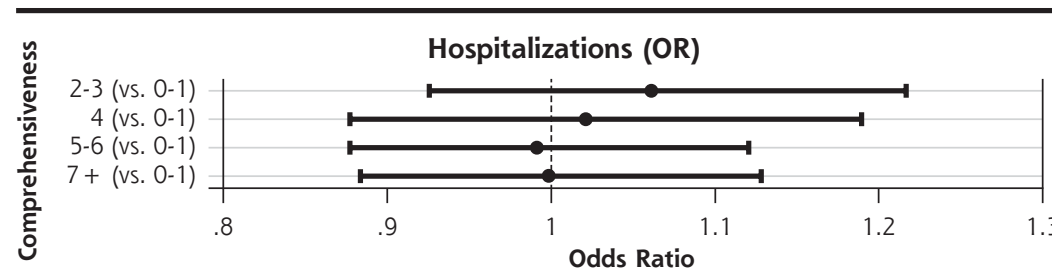

In (Part A \& B Expenses)
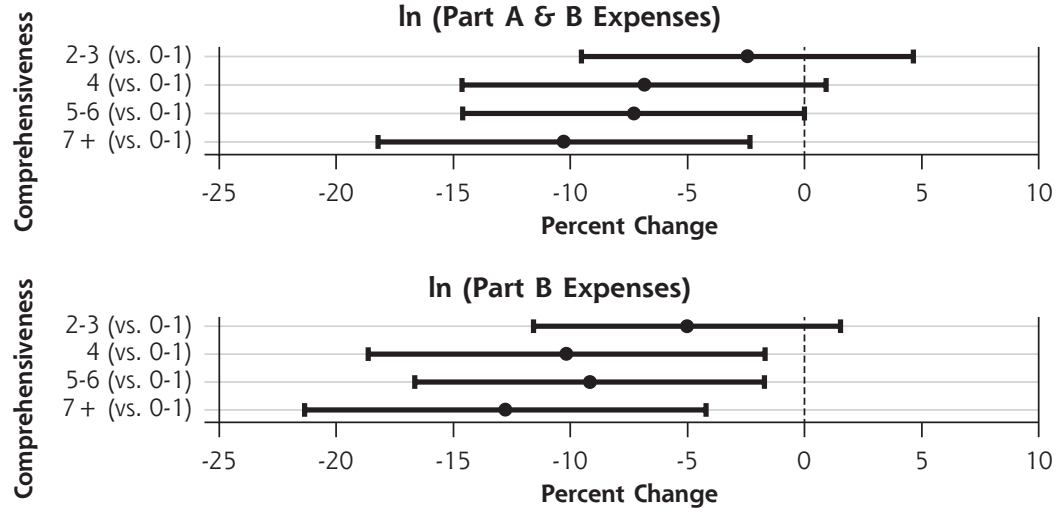

In = natural logarithm; OR = Odds ratio

2011 Medicare Claims Data; Sample consists of recertifying family physicians, $n=1,133$.

Estimates of percent change and odds ratio are adjusted for patient and physician characteristics; full model in Supplemental Appendix 1, http://www.annfammed.org/content/13/3/206/suppl/DC1.

Figure 2. Association between BETOS score and measures of hospitalization and expenses.

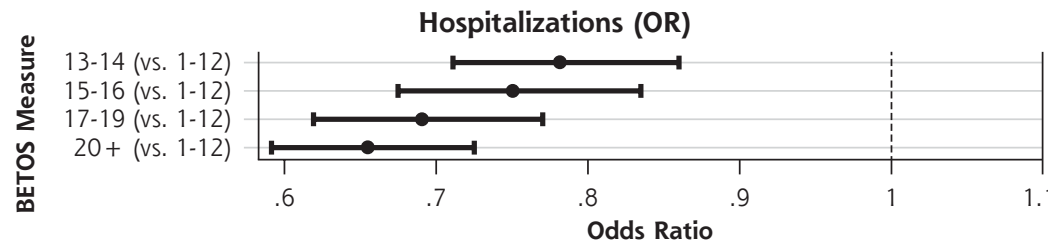

In (Part A \& B Expenses)
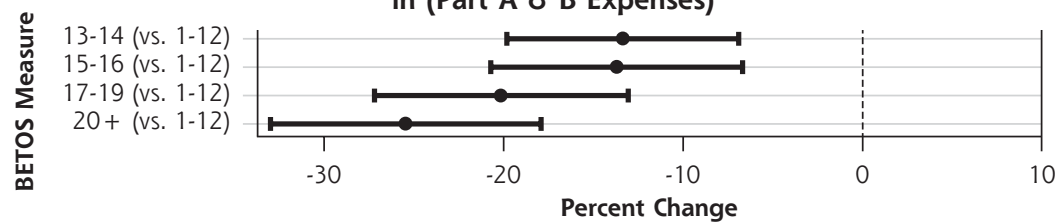

In (Part B Expenses)
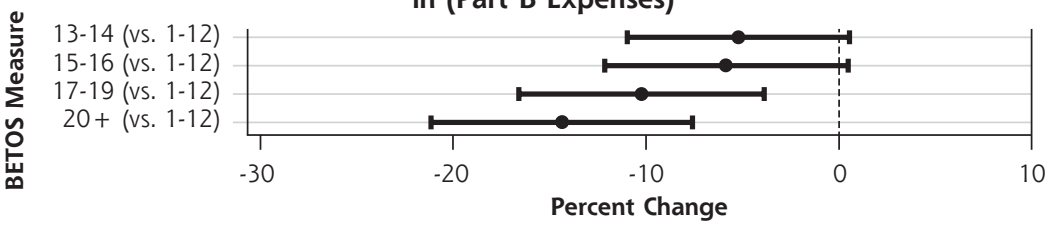

BETOS = Berenson-Eggars Type of Service; In = natural logarithm; OR = odds ratio.

2011 Medicare Claims Data; Sample consists of the full sample of family physicians ( $n=3,660$ ).

Estimates of percent change and odds ratio are adjusted for patient and physician characteristics; full model in Supplemental Appendix 1, http://www.annfammed.org/content/13/3/206/suppl/DC1. and multimorbidity relative to the broader population, and also one increasing in proportion across family medicine panels.

It is important to note that both our comprehensiveness measures fail to capture all important aspects of comprehensiveness, or to cover the entire spectrum of ages, problems, and modalities encompassed by family medicine. This results in greater likelihood of Type II error, or underestimation of the actual effects of comprehensiveness on outcome. Finally, it is possible that the highest performing family physicians, those whose patients might naturally achieve better outcomes, would self-select into the study cohort offering the most services, while those with the least natural ability might selfselect into the group offering the least the fewest services.

Both these findings and their limitations beg for further exploration of the measurement of comprehensiveness and its relationship to cost, access, and quality of care. Furthermore, they should encourage policy makers to consider training and payment policies that support more robust and comprehensive practice, as 1 means of bending the cost curve and achieving the nation's Triple Aim. ${ }^{31}$ Similarly, family physician leaders and training institutions must ponder how to help preserve broad generalist training in an age of increasingly heterogeneous and restrictive practice opportunities for its graduates.

To read or post commentaries in response to this article, see it online at http://www.annfammed.org/ content/13/3/206.

Key words: comprehensive health care; cost analysis; general practice; family medicine

Submitted October 8, 2014; submitted, revised, February 6, 2015; accepted February 19, 2015. 
Prior presentations: Portions of the findings reported have been presented at the following conferences: American Association of Medical Colleges Annual Workforce Meeting, 2014, Washington DC; AcademyHealth Annual Research Meeting, 2014, San Diego, California.

Funding support: The Robert Graham Center received support for this study from the American Board of Family Medicine in the form of a contract for collaborative research.

Disclaimer: The information and opinions contained in research from the Robert Graham Center do not necessarily reflect the views or policy of the American Academy of Family Physicians.

Supplementary materials: Available at http://www.AnnFamMed. org/content/13/3/206/suppl/DC1/.

\section{References}

1. Institute for Healthcare Improvement. The IHI Triple Aim. http:// www.ihi.org/Engage/Initiatives/TripleAim/pages/default.aspx. Accessed May 1, 2015.

2. Starfield B, Shi L, Macinko J. Contribution of primary care to health systems and health. Milbank Q. 2005;83(3):457-502.

3. Macinko J, Starfield B, Shi L. The contribution of primary care systems to health outcomes within Organization for Economic Cooperation and Development (OECD) countries, 1970-1998. Health Serv Res. 2003;38(3):831-865.

4. Donaldson MS, Yordy KD, Lohr KN, Vanselow NA. Primary Care: America's Health in a New Era. Washington, DC: National Academies Press; 1996

5. World Health Organization (WHO). The World Health Report 2008 - Primary Health Care - Now More than Ever. 2008. http://www.who. int/whr/2008/en/. Accessed Oct 3, 2013.

6. Tong STC, Makaroff LA, Xierali IM, et al. Proportion of family physicians providing maternity care continues to decline. J Am Board Fam Med. 2012;25(3):270-271.

7. Tong ST, Makaroff LA, Xierali IM, Puffer JC, Newton WP, Bazemore AW. Family physicians in the maternity care workforce: factors influencing declining trends. Matern Child Health J. 2013;17(9):1576-1581.

8. Bazemore AW, Makaroff LA, Puffer JC, et al. Declining numbers of family physicians are caring for children. J Am Board Fam Med. 2012;25(2):139-140

9. Xierali IM, Puffer JC, Tong STC, Bazemore AW, Green LA. The percentage of family physicians attending to women's gender-specific health needs is declining. J Am Board Fam Med. 2012;25(4):406-407.

10. Cohen D, Coco A. Declining trends in the provision of prenatal care visits by family physicians. Ann Fam Med. 2009;7(2):128-133.

11. Cohen D, Coco A. Trends in the provision of preventive women's health services by family physicians. Fam Med. 2011;43(3):166-171.

12. Petterson S, Peterson L, Phillips RL, et al. One in fifteen family physicians principally provide emergency or urgent care. J Am Board Fam Med. 2014;27(4):447-448.

13. Phillips RL Jr, Green LA. Making choices about the scope of family practice. J Am Board Fam Pract. 2002;15(3):250-254.

14. Bazemore AW, Petterson SM, Johnson N, et al. What services do family physicians provide in a time of primary care transition? J Am Board Fam Med. 2011;24(6):635-636.

15. Martin JC, Avant RF, Bowman MA, et al.; Future of Family Medicine Project Leadership Committee. The Future of Family Medicine: a collaborative project of the family medicine community. Ann Fam Med. 2004;2(Suppl 1):S3-S32.
16. Phillips RL Jr, Pugno PA, Saultz JW, et al. Health is primary: Family medicine for America's health. Ann Fam Med. 2014;12(Suppl 1):S1-S12.

17. Chen PG-C, Mehrotra A, Auerbach DI. Do we really need more physicians? Responses to predicted primary care physician shortages. Med Care. 2014;52(2):95-96.

18. Chen PG-C, Mehrotra A, Auerbach DI. Response: effectiveness in primary care is paramount, but need not come at the expense of efficiency. Med Care. 2014;52(2):99-100.

19. Centers for Medicare and Medicaid Services. CMS.gov. Berenson Eggers Type of Service (BETOS). Published Nov 2014. http://www. cms.gov/Medicare/Coding/HCPCSReleaseCodeSets/BETOS.html.

20. Pham HH, Schrag D, O'Malley AS, Wu B, Bach PB. Care patterns in Medicare and their implications for pay for performance. $N$ Engl J Med. 2007;356(11):1130-1139.

21. Kuo Y-F, Sharma G, Freeman JL, Goodwin JS. Growth in the care of older patients by hospitalists in the United States. N Engl J Med. 2009;360(11):1102-1112.

22. Charlson ME, Pompei P, Ales KL, Mackenzie CR. A new method of classifying prognostic comorbidity in longitudinal studies: development and validation. J Chronic Dis. 1987;40(5):373-383. 10.1016/0021-9681(87)90171-8.

23. Washington Wyoming Alaska Montana Idaho Rural Health Research Center. Rural Urban Commuting Area Codes Data. http://depts. washington.edu/uwruca/ruca-data.php. Accessed Nov 13, 2013.

24. The Dartmouth Institute for Health Policy and Clinical Practice. Dartmouth atlas of health care. http://www.dartmouthatlas.org

25. Martin JC, Avant RF, Bowman MA, et al.; Future of Family Medicine Project Leadership Committee. The Future of Family Medicine: a collaborative project of the family medicine community. Ann Fam Med. 2004;2(Suppl 1):S3-S32.

26. Green LA, Jones SM, Fetter G Jr, Pugno PA. Preparing the personal physician for practice: changing family medicine residency training to enable new model practice. Acad Med. 2007;82(12):1220-1227.

27. Colwill JM, Cultice JM, Kruse RL. Will generalist physician supply meet demands of an increasing and aging population? Health Aff (Millwood). 2008;27(3):w232-w241.

28. Palmer VJ, Gunn JM. Arranging generalism in the 2020 primary care team. 2009. http://anu.edu/aphcri/Spokes_Research_Program/ Stream_Ten/S10_PalmerGunn_25.pdf. Accessed Sep 26, 2013.

29. Bodenheimer T, Pham HH. Primary care: current problems and proposed solutions. Health Aff (Millwood). 2010;29(5):799-805.

30. Barr VJ, Robinson S, Marin-Link B, et al. The expanded Chronic Care Model: an integration of concepts and strategies from population health promotion and the Chronic Care Model. Hosp Q. 2003; 7(1):73-82.

31. Stange KC. The generalist approach. Ann Fam Med. 2009;7(3): 198-203.

32. Petterson SM, Bazemore AW, Phillips RL, et al. Rewarding family medicine while penalizing comprehensiveness? Primary care payment incentives and health reform: the Patient Protection and Affordable Care Act (PPACA). J Am Board Fam Med. 2011;24(6):637-638.

33. Pronovost PJ, Needham DM, Waters $\mathrm{H}$, et al. Intensive care unit physician staffing: financial modeling of the Leapfrog standard. Crit Care Med. 2006;34(3)(Suppl):S18-S24.

34. Bazemore AW, Burke M, Xierali IM, et al. Establishing a baseline: health information technology adoption among family medicine diplomates. J Am Board Fam Med. 2011;24(2):132-132.

35. Xierali IM, Phillips RL Jr, Green LA, Bazemore AW, Puffer JC. Factors influencing family physician adoption of electronic health records (EHRs). J Am Board Fam Med. 2013;26(4):388-393. 